\title{
Size and shape of supported zirconia nanoparticles determined by x-ray photoelectron spectroscopy
}

\author{
F. Yubero, ${ }^{\text {a) }}$ C. Mansilla, F. J. Ferrer, J. P. Holgado, and A. R. González-Elipe \\ Instituto de Ciencia de Materiales de Sevilla (CSIC-U. Sevilla), Américo Vespucio 49, \\ E-41092 Sevilla, Spain
}

(Received 13 March 2007; accepted 11 May 2007; published online 26 June 2007)

\begin{abstract}
The initial stages of growth of zirconia nanoparticles deposited on $\mathrm{SiO}_{2}, \mathrm{Y}_{2} \mathrm{O}_{3}$, and $\mathrm{CeO}_{2}$ substrates have been studied by the $\mathrm{x}$-ray photoelectron spectroscopy peak shape analysis. $\mathrm{ZrO}_{2}$ was deposited by plasma decomposition of a volatile $\mathrm{Zr}(\mathrm{OtBu})_{4}$ precursor. The electronic interactions at each particular interface formed have been followed by means of the modified Auger parameter of the deposited $\mathrm{Zr}$ cations. They were quantified by means of Wagner plots and the chemical state vectors of the systems. The observed changes in these local electronic probes as the amount of deposit was increased have been correlated to the particular $\mathrm{ZrO}_{2}$ nanostructures identified on each substrate considered. A Volmer-Weber (islands) growth mechanism has been found for all the substrates considered. Moreover, clear indications have been found of a columnar growth for the case of $\mathrm{ZrO}_{2}$ deposited on $\mathrm{SiO}_{2}$. () 2007 American Institute of Physics. [DOI: 10.1063/1.2749482]
\end{abstract}

\section{INTRODUCTION}

During the last decade, the advent of an increasing interest in the field of nanomaterials has fostered the development of methods or, in its case, the adaptation of classical tools for their characterization. Typically, information is centered on the size and morphology of the formed nanostructures and, for supported particles, also on the electronic or bonding interactions appearing at the interface with the support. X-ray photoelectron spectroscopy (XPS) has been traditionally used for the surface analysis of materials. However, the lateral resolution of this technique is still limited, at least one order of magnitude higher than the size typically attributed to nanomaterials (the highest limit usually considered is of less than $\sim 100 \mathrm{~nm}$ ). Notwithstanding this limitation, in previous works dealing with small oxide nanoparticles deposited on different substrates, we have shown that average values of particle heights (in the range of a few nanometers) and the degree of the substrate coverage can be obtained by the socalled XPS peak shape analysis. ${ }^{1,2}$ This approach has been applied, for example, to the case of small zinc oxide, ${ }^{3}$ tin oxide, ${ }^{4}$ and cerium oxide ${ }^{5}$ particles deposited on different substrates. ${ }^{3-5}$

In this paper we want to go a step forward by comparing the results obtained with the peak shape analysis methodology with the evolution of electronic parameters of $\mathrm{Zr}$ (i.e., binding energy and Auger parameter ${ }^{6-8}$ of characteristic electron photoemitted peaks) as a function of the amount of deposited zirconia moieties. In previous publications we have shown that these parameters change with the size of the particles and that this variation may provide interesting clues for the electronic interactions that develop at the interface between the deposited phase and the substrate. ${ }^{9-13}$ In the present work, it will be shown that the comparison between these two sets of data may provide information not only on the size of the particles, but also on their shape.

\footnotetext{
${ }^{a)}$ Electronic mail: yubero@icmse.csic.es
}

Nowadays, zirconium dioxide $\left(\mathrm{ZrO}_{2}\right)$ receives much attention in research fields such as fuel cell technology, where it is used as a solid electrolyte conducting material, ${ }^{14}$ or electronics, where it is a candidate to replace silicon dioxide as gate insulator material. ${ }^{15}$ In both cases, a challenge is to improve the performance of the devices while the thickness of zirconia layers is decreased. This obliges a strict control of the microstructure of the deposited films when they are implemented in such devices. This is the reason why a detailed understanding of the growth mechanisms and electronic interactions at the formed interfaces are of utmost interest.

Thus, in this paper we show results that correspond to the initial stages of growth of $\mathrm{ZrO}_{2}$ nanoparticles prepared at room temperature by plasma enhanced chemical vapor deposition (PECVD) on $\mathrm{SiO}_{2}, \mathrm{Y}_{2} \mathrm{O}_{3}$, and $\mathrm{CeO}_{2}$ substrates. The initial stages of growth have been studied in situ by XPS inelastic peak shape analysis. ${ }^{1,2}$ Besides, the electronic interactions at each particular interface formed have been followed by means of the Auger parameter of the deposited $\mathrm{Zr}$ cation. The observed changes in this local electronic probe have been correlated to the particular growth mechanism of the $\mathrm{ZrO}_{2}$ deposits on each substrate considered. The idea is to describe the size and shape of the initial nuclei formed during the deposition as a function of the amount of the deposited material and the type of substrate. The characterization of these nuclei is important because their size, shape, and dispersion degree on the surface are critical for the control of the microstructure of the thin films. The interest of this type of analysis is not limited to thin film nucleation as in the present example, but can be of interest for other situations where the knowledge of the shape and size of supported particles may be important (e.g., catalysts, supported nanoparticles, etc.). In this regard, it is interesting to recall that in many experimental situations it is not possible to asses the particle size and shape of deposited nanoparticles by means of classical microscopy methods. This is the case 

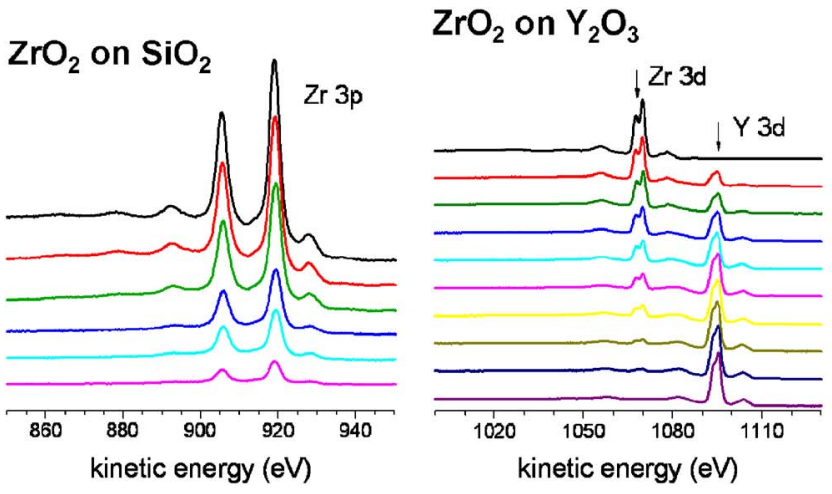

when, with materials with a high electron density or high surface roughness, electron microscopy or atomic force microscopy fails to differentiate between the structures of a support from those of the supported nanoparticles. We believe that in these cases the proposed methodology can be very useful for both an electronic and a morphological characterization of supported nanoparticles.

\section{EXPERIMENT}

Nanometric $\mathrm{ZrO}_{2}$ particles were deposited at room temperature by decomposition of $\mathrm{Zr}(\mathrm{OtBu})_{4}$ (a volatile $\mathrm{Zr}$ organometallic precursor) in a microwave plasma of oxygen at room temperature. Precursor and oxygen pressures during deposition were $\sim 1 \times 10^{-5}$ and $\sim 1 \times 10^{-3}$ mbar, respectively. Under these conditions, the deposition rates were $0.1-0.2 \mathrm{~nm} / \mathrm{min}$. After each deposition process, the samples were always exposed for a few minutes to the plasma of oxygen without a precursor to ensure full oxidation and removal of any carbonaceous trace remaining on the surface.

Three different substrates were used: $\mathrm{SiO}_{2}, \mathrm{Y}_{2} \mathrm{O}_{3}$, and $\mathrm{CeO}_{2}$ thin films ( $100 \mathrm{~nm}$ thick) grown on $\mathrm{Si}(100)$ polished wafers. The $\mathrm{SiO}_{2}$ substrate was thermally grown. The $\mathrm{Y}_{2} \mathrm{O}_{3}$ substrate was deposited by ion beam induced chemical vapor deposition $^{16}$ and $400 \mathrm{eV} \mathrm{O}_{2}{ }^{+}$ions. $\mathrm{CeO}_{2}$ was deposited by electron beam evaporation of $\mathrm{CeO}_{2}$ sintered pellets. The substrates were cleaned first by $3 \mathrm{keV} \mathrm{O}_{2}{ }^{+}$bombardment until there is a complete removal of surface contamination and, afterwards, by oxygen plasma treatment to achieve a complete oxidation of the substrate, as determined by XPS. The size of the substrates was $\sim 1 \mathrm{~cm}^{2}$. The XPS analyzed area was a circle of $\sim 6 \mathrm{~mm}$ diameter at the center of the sample. The deposition of $\mathrm{ZrO}_{2}$ was performed simultaneously on the three substrates to produce several sets of samples, one after each deposition process. After the film growth, the samples were transferred to the analysis chamber (base pressure of $\sim 5 \times 10^{-10}$ mbar) under UHV conditions, where $\mathrm{X}$-ray photoelectron spectra were recorded with a VG-ESCALAB 210 electron spectrometer. The surface was irradiated with $\mathrm{Al} K \alpha$ $\mathrm{X}$ rays incident at the angle of $54^{\circ}$ with respect to the surface normal. The excited electrons were collected normal to the surface with an $\sim 1 \mathrm{eV}$ energy resolution. Long scans including main peaks and loss tails were recorded for the Ce $3 d, \mathrm{Zr}$ $3 p, \mathrm{Zr} 3 d$, Y $3 d$, and $\mathrm{Zr} L M M$ signals to study the initial stages of growth by the XPS peak shape analysis using the QUASES software. ${ }^{17}$ The TPP2M formula ${ }^{18}$ was used for the

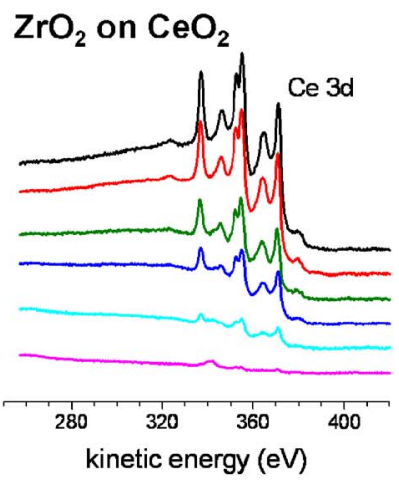

FIG. 1. (Color online) Experimental spectra acquired for the determination of the growth mode by the inelastic XPS peak shape analysis.

determination of electron inelastic mean free paths $\lambda$. Thus, the following values have been used: $9.2 \AA$ for the Ce $3 d$ signal, 17.8 $\AA$ for the $\mathrm{Zr} 3 p, 20.4 \AA$ for the $\mathrm{Zr} 3 d$ and Y $3 d$ signals, and $30.6 \AA$ for the $\mathrm{Zr} L M M$. Reference samples were either the clean substrates or a thick $\mathrm{ZrO}_{2}$ layer after more than $20 \mathrm{~nm}$ of deposited $\mathrm{ZrO}_{2}$ on either substrate.

\section{RESULTS AND DISCUSSIONS}

\section{A. Initial stages of growth of $\mathrm{ZrO}_{2}$ nanoparticles on $\mathrm{SiO}_{2}, \mathrm{Y}_{2} \mathrm{O}_{3}$, and $\mathrm{CeO}_{2}$ substrates}

As an example of the quality of the spectra used in the XPS peak shape analysis, Fig. 1 shows the recorded $\mathrm{Zr} 3 p$ signals measured for the system $\mathrm{ZrO}_{2} / \mathrm{SiO}_{2}$, the $\mathrm{Zr} 3 d$ and $\mathrm{Y}$ $3 d$ signals corresponding to the $\mathrm{ZrO}_{2} / \mathrm{Y}_{2} \mathrm{O}_{3}$ system, and the Ce $3 d$ spectra for the $\mathrm{ZrO}_{2} / \mathrm{CeO}_{2}$ system. Note that as successive deposition steps are performed, the intensity of the $\mathrm{Zr}$ peaks increases, first the elastic part (without inelastic losses) and afterwards the background intensity in a $\sim 100 \mathrm{eV}$ wide energy range below the main zero-loss peaks. Regarding the spectra from the substrates, the intensity of the main peak drops, while the background intensity below the peak increases as the zirconia particles grow on top of the substrate.

As it has been shown in numerous papers by Tougaard (see Refs. 1 and 2 and references therein), these changes can be used to determine the nanostructure of the deposits. Thus, the measured spectra $J(E)$, the primary excitation spectra $F(E)$, the in-depth concentration profile $c(x)$, and the differential inelastic scattering cross section $K(T)$ are linked within the electron transport theory. ${ }^{1,2}$ In the present analysis, the concentration profile $c(x)$ is given by the surface coverage $c$ that varies from 0 to 1 ( $c=1$ indicates a full surface coverage) and the averaged island height $h$. Thus, the quantification of each sample will be expressed as the surface coverage $c$, which indicates the fraction of the surface that is covered with the deposit, and the island height $h$, which indicates the average island height of the $\mathrm{ZrO}_{2}$ aggregates. The normalized cross section $\lambda K(T)$ was determined from an analysis of a reflection electron energy loss spectroscopy (REELS) spectrum taken at a $1600 \mathrm{eV}$ primary energy from a thick $\mathrm{ZrO}_{2}$ sample (not shown). ${ }^{19}$

We have applied the QUASES software package ${ }^{17}$ that enables a straightforward analysis of the spectra shown in Fig. 1. It is found that the $\mathrm{ZrO}_{2}$ grows in the form of aggregates on the three substrates considered. The determined averaged 


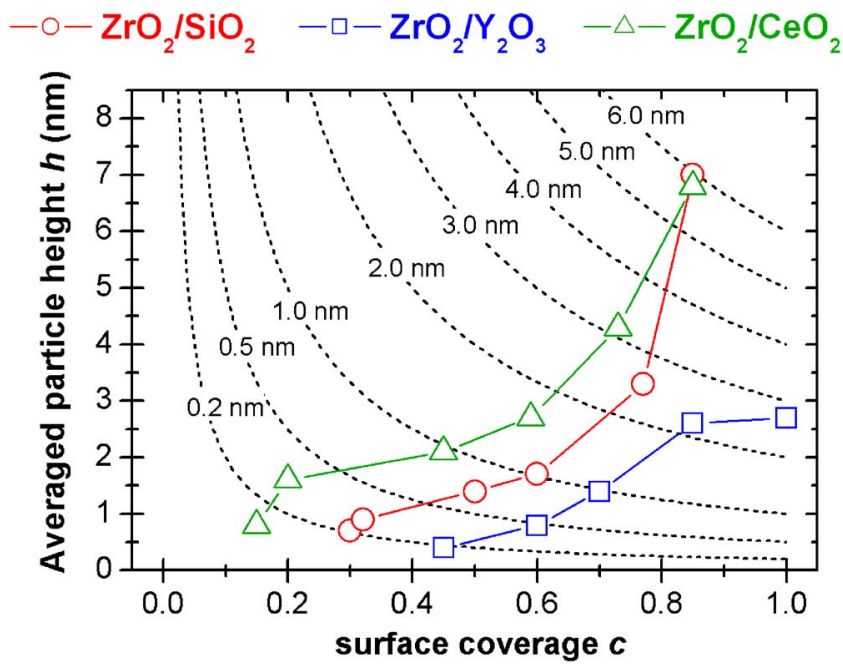

FIG. 2. (Color online) Initial stages of growth of $\mathrm{ZrO}_{2}$ deposited on $\mathrm{SiO}_{2}$, $\mathrm{Y}_{2} \mathrm{O}_{3}$, and $\mathrm{CeO}_{2}$ by plasma decomposition of a volatile $\mathrm{Zr}(\mathrm{OtBu})_{4}$ precursor; surface coverage vs island height determined from the XPS peak shape analysis using the QUASES software is reported. Dashed lines indicate fixed amounts of deposited $\mathrm{ZrO}_{2}$.

island height and surface coverage for the growth of $\mathrm{ZrO}_{2}$ on $\mathrm{SiO}_{2}, \mathrm{Y}_{2} \mathrm{O}_{3}$, and $\mathrm{CeO}_{2}$ are shown in Fig. 2. The heights and surface coverages increase gradually as the $\mathrm{ZrO}_{2}$ loads increase. It is found that for the same amount of deposited $\mathrm{ZrO}_{2}$ (dashed lines in Fig. 2) the surface coverage increases following the trend $\mathrm{CeO}_{2}<\mathrm{SiO}_{2}<\mathrm{Y}_{2} \mathrm{O}_{3}$. Note that in the case of $\mathrm{ZrO}_{2} / \mathrm{Y}_{2} \mathrm{O}_{3}$ a full coverage is achieved when $\sim 3 \mathrm{~nm}$ of $\mathrm{ZrO}_{2}$ is deposited on the substrate. However, for the systems $\mathrm{ZrO}_{2} / \mathrm{SiO}_{2}$ and $\mathrm{ZrO}_{2} / \mathrm{CeO}_{2}$ only $80 \%$ of surface coverage is achieved when $\sim 6 \mathrm{~nm}$ of $\mathrm{ZrO}_{2}$ is deposited on the surface.

The obtained results could be justified using thermodynamic arguments. The free energy of formation of $\mathrm{Y}_{2} \mathrm{O}_{3}$ $(-1905 \mathrm{~kJ} / \mathrm{mol})$ is significantly higher than that of $\mathrm{ZrO}_{2}$ $(-1101 \mathrm{~kJ} / \mathrm{mol})$, while those of $\mathrm{CeO}_{2}(-1089 \mathrm{~kJ} / \mathrm{mol})$ and $\mathrm{SiO}_{2}(-911 \mathrm{~kJ} / \mathrm{mol})$ are similar to that of $\mathrm{ZrO}_{2}$. If we assume that surface tension follows the same trend as the free energy of formation of the corresponding oxides, $\mathrm{ZrO}_{2}$ wetting should be favored in $\mathrm{Y}_{2} \mathrm{O}_{3}$ with respect to $\mathrm{CeO}_{2}$ or $\mathrm{SiO}_{2} \cdot{ }^{20,21}$

\section{B. Electronic effects at the $\mathrm{ZrO}_{2} / \mathrm{MO}_{x}(\mathrm{M}: \mathrm{Si}, \mathrm{Y}, \mathrm{Ce})$ interfaces}

The measurement of the photoelectron peak positions to determine binding energies of surface elements and their chemical states is a typical use of XPS. Besides, the Auger parameter has also been recognized as a very powerful tool to get information about the electronic interactions and the polarizability of the medium around the photoemitting atom. ${ }^{8}$ At oxide/oxide interfaces formed by nanometric particles of an oxide deposited on another oxide, the use of this second parameter has been proven to be very useful to describe the type of interactions appearing at the interface. ${ }^{9-13}$ In this work we have studied the relaxation effects of the $\mathrm{Zr}^{4+}$ ions at the different interfaces. This was done by measuring the binding energy of the $\mathrm{Zr} 3 d_{5 / 2}$ peaks $\mathrm{BE}\left(\mathrm{Zr} 3 d_{5 / 2}\right)$,
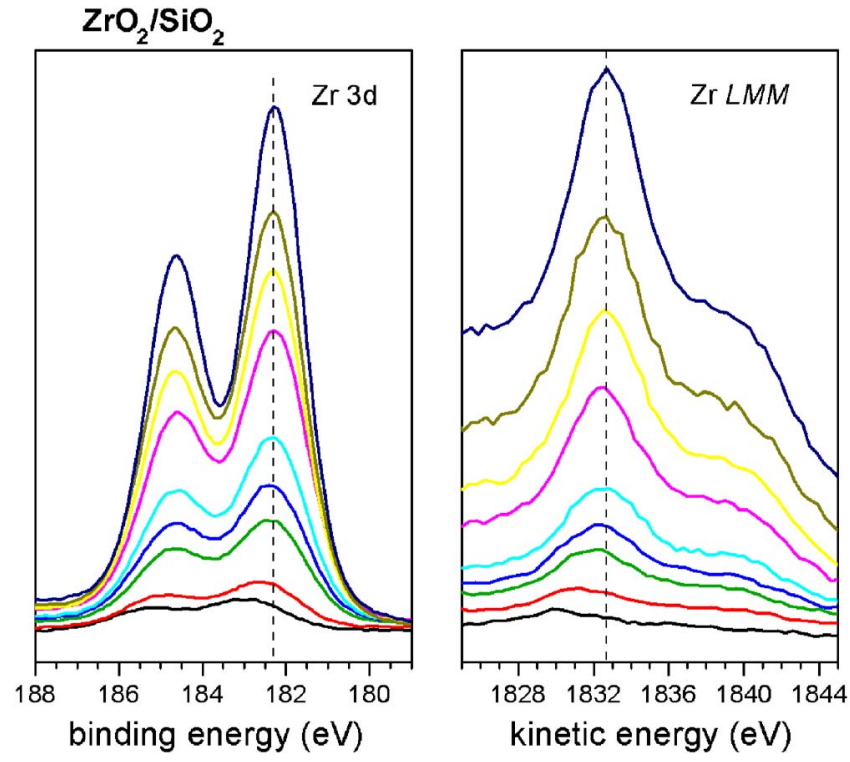

FIG. 3. (Color online) $\mathrm{Zr} 3 d$ and $\mathrm{Zr} L M M$ Auger signals coming from the $\mathrm{Zr}$ atoms at the successive depositions of $\mathrm{ZrO}_{2}$ on $\mathrm{SiO}_{2}$. Vertical dashed lines indicate the position of the corresponding peaks of bulk $\mathrm{ZrO}_{2}$.

the kinetic energy of the $\operatorname{Zr} L M M$ peaks $\operatorname{KE}\left(\operatorname{Zr} L M_{4,5} M_{4,5}\right)$, and the corresponding modified Auger parameter $\alpha^{\prime}$, which for $\mathrm{Zr}^{4+}$ species is defined as

$$
\alpha^{\prime}=\mathrm{BE}\left(\mathrm{Zr} 3 d_{5 / 2}\right)+\mathrm{KE}\left(\mathrm{Zr} L M_{4,5} M_{4,5}\right) .
$$

At this point, it is also worth defining the changes in $\alpha^{\prime}$ $\left(\Delta \alpha^{\prime}\right)$ for the $\mathrm{Zr}^{4+}$ ions with respect to bulk $\mathrm{ZrO}_{2}$ as

$$
\Delta \alpha^{\prime}=\alpha^{\prime}(\mathrm{Zr}-\mathrm{O}-\mathrm{M})-\alpha^{\prime}(\mathrm{Zr}-\mathrm{O}-\mathrm{Zr}),
$$

where $\alpha^{\prime}(\mathrm{Zr}-\mathrm{O}-M)$ and $\alpha^{\prime}(\mathrm{Zr}-\mathrm{O}-\mathrm{Zr})$ refer to the modified Auger parameter of the $\mathrm{Zr}^{4+}$ ions at the particular $\mathrm{ZrO}_{2} / M \mathrm{O}_{x}$ interface or bulk $\mathrm{ZrO}_{2}$, respectively.

To show the reliability in the determination of these parameters, Fig. 3 shows a series of $\mathrm{Zr} 3 d$ and $\mathrm{Zr} L M M$ peaks for successive depositions of $\mathrm{ZrO}_{2}$ on the surface of $\mathrm{SiO}_{2}$. It is apparent that both series of peaks depict a clear variation in their position as the amount of deposited material increases, mainly in the very initial stages. The positions measured for the highest coverage correspond to the values of bulk $\mathrm{ZrO}_{2}{ }^{22-24}$ These measurements were made for the three systems, and the values determined for the Auger parameter in each case are plotted in Fig. 4. It shows the variation of the Auger parameter for the $\mathrm{Zr}^{4+}$ ions at the different interfaces as a function of the normalized intensity ratio (peak areas divided by the corresponding photoexcitation cross

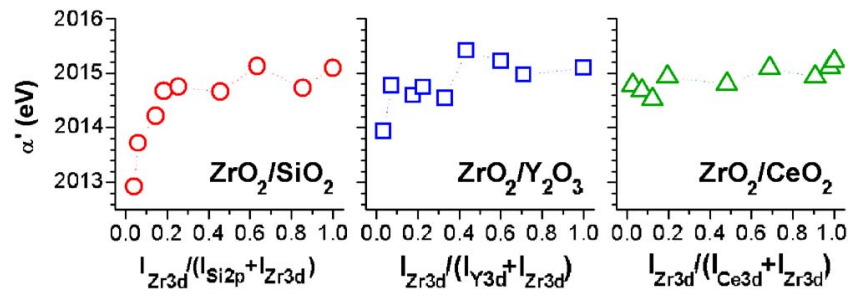

FIG. 4. (Color online) Variation of the modified Auger parameter of the $\mathrm{Zr}^{4+}$ ions $\alpha^{\prime}$ with the amount of $\mathrm{ZrO}_{2}$ deposited on $\mathrm{SiO}_{2}, \mathrm{Y}_{2} \mathrm{O}_{3}$, and $\mathrm{CeO}_{2}$ substrates. 


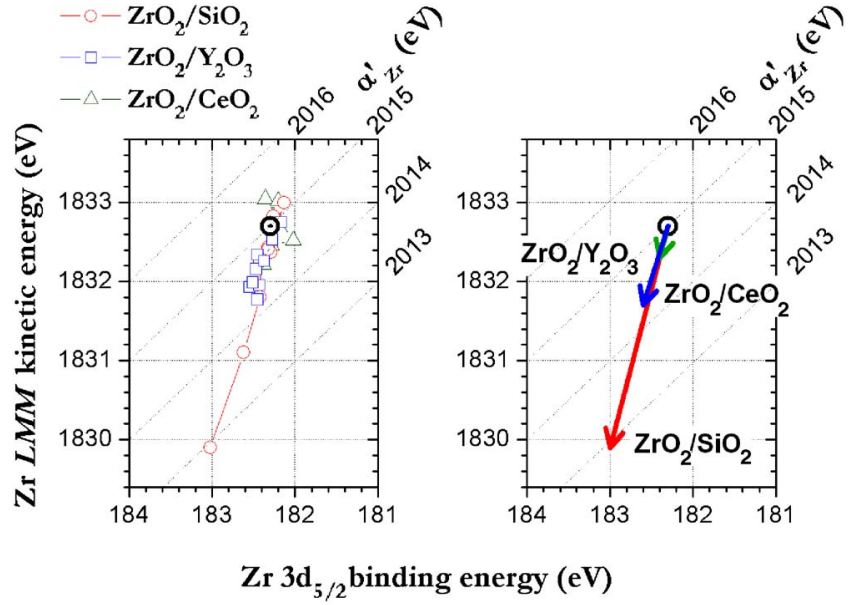

FIG. 5. (Color online) Wagner plots including experimental data (left) and chemical state vectors (right) obtained for the $\mathrm{ZrO}_{2} / \mathrm{SiO}_{2}, \mathrm{ZrO}_{2} / \mathrm{Y}_{2} \mathrm{O}_{3}$, and $\mathrm{ZrO}_{2} / \mathrm{CeO}_{2}$ systems.

sections ${ }^{25}$ ), as indicated in the figure. Error bars of $\pm 0.2 \mathrm{eV}$ are estimated due to the large width of the $\mathrm{Zr} L M M$ signal. Note how in all cases, the modified Auger parameter increases as the amount of $\mathrm{ZrO}_{2}$ deposited on either substrate increases. However, the size of this effect differs for the different substrates. This effect is very strong for the $\mathrm{ZrO}_{2} / \mathrm{SiO}_{2}$ system, where $\alpha^{\prime}$ increases from $\sim 2012.9 \mathrm{eV}$ for the smallest amount of $\mathrm{ZrO}_{2}$ deposited on $\mathrm{SiO}_{2}$ to the value reported for the bulk $\mathrm{ZrO}_{2}$ matrix of $\sim 2015.0 \mathrm{eV}$, i.e., the maximum variation observed for the modified Auger parameter $\Delta \alpha_{\max }^{\prime}$ $=-2.1 \mathrm{eV}$. This effect is weaker for $\mathrm{ZrO}_{2}$ deposited on $\mathrm{Y}_{2} \mathrm{O}_{3}$ $\left(\Delta \alpha_{\max }^{\prime}=-0.8 \mathrm{eV}\right)$ and even weaker for the $\mathrm{ZrO}_{2} / \mathrm{CeO}_{2}$ system $\left(\Delta \alpha_{\max }^{\prime}=-0.4 \mathrm{eV}\right)$. A way of characterizing the observed electronic behavior of $\mathrm{Zr}^{4+}$ ions at these interfaces is representing the changes in the electronic parameters in Wagner plots ${ }^{6,7}$ in the form of "chemical state vectors" (CSVs). ${ }^{19,26}$ The corresponding plots are shown in Fig. 5. Coordinates of the CSVs are listed in Table I.

In the case of $\mathrm{Zr}$ ions at the $\mathrm{ZrO}_{2} / \mathrm{SiO}_{2}$ and $\mathrm{ZrO}_{2} / \mathrm{Y}_{2} \mathrm{O}_{3}$ interfaces, final state effects are mainly responsible for the observed relaxation (slope of the CSV of $\sim 3$ ). ${ }^{7,8,16}$ In the cases of $\mathrm{ZrO}_{2} / \mathrm{CeO}_{2}$ the error bars $( \pm 0.2 \mathrm{eV})$ do not allow to make any decision about the origin of this relaxation.

\section{Correlation between nanostructure and polarization effects}

A first issue that deserves a comment refers to the variations in $\alpha^{\prime}$ for the different oxide/oxide systems studied here. The maximum variation is found for the $\mathrm{ZrO}_{2} / \mathrm{SiO}_{2}$ system (i.e., $-2.1 \mathrm{eV}$ ), while this is only $-1.0 \mathrm{eV}$ for $\mathrm{ZrO}_{2} / \mathrm{Y}_{2} \mathrm{O}_{3}$ and only $-0.4 \mathrm{eV}$ for $\mathrm{ZrO}_{2} / \mathrm{CeO}_{2}$. In previous publications we have thoroughly discussed about the factors that influence the value of $\alpha^{\prime}$ of small particles of an oxide deposited on another oxide acting as support. ${ }^{9-13}$ Here, we want to refer to the issues that will be used for the evaluation of the shape of $\mathrm{ZrO}_{2}$ particles deduced by a combined analysis of the peak shape and the variations in the Auger parameter as a function of the amount of deposited material. For other aspects of the interpretation of the changes in the Auger parameter, we refer to these previous publications. ${ }^{9-13}$ Changes in $\alpha^{\prime}$ for $M \mathrm{O} / M^{\prime} \mathrm{O}$ systems can be due to two types of contributions. A first one is due to the different polarization of the two oxides brought in contact $\left[\Delta \alpha^{\prime}(p)\right]$. The second is the bonding contribution due to the effect of the specific electronic interactions developing at the interface when the size of the deposited particle is very small $\left[\Delta \alpha^{\prime}(b)\right]$. Thus,

$$
\Delta \alpha^{\prime}=\Delta \alpha^{\prime}(p)+\Delta \alpha^{\prime}(b) .
$$

The maximum polarization contribution can be estimated according to ${ }^{27}$

$$
\Delta \alpha^{\prime}(p)_{\max }=\frac{11.4}{d}\left(\frac{1}{n_{l}^{2}}-\frac{1}{n_{s}^{2}}\right),
$$

where, in a first approximation, $d$ can be taken as the $\mathrm{Zr}-\mathrm{O}$ bond distance, and $n_{l}$ and $n_{s}$ are the refractive indices of, respectively, the layer and substrate materials. The calculated $\Delta \alpha^{\prime}(p)$ values for the three $\mathrm{ZrO}_{2} / M \mathrm{O}_{x}$ systems have been summarized in Table I. It is apparent that the most significant expected change occurs for $\mathrm{SiO}_{2}$, the material with the maximum variation in refractive index with respect to $\mathrm{ZrO}_{2}$. It has been currently assumed that the total change in $\alpha^{\prime}$ (i.e., the experimentally determined $\Delta \alpha^{\prime}$ ) is due to the contribution of both the different polarizations of the substrate and deposited particles and the effect of specific electronic interactions developing at the interface when the size of the particle is very small (i.e., bonding contribution to $\Delta \alpha^{\prime}$ ). It is possible to estimate the changes in the bonding contributions $\Delta \alpha^{\prime}(b)$ for the three interface systems using Eqs. (2) and (3). These changes have been summarized in Table I. A monolayer size of $4.4 \AA$ (twice the $\mathrm{Zr}-\mathrm{O}$ distance in $\mathrm{ZrO}_{2}$ ) and refractive indices of 1.45, 1.79, 2.20, and 2.05 for $\mathrm{SiO}_{2}, \mathrm{Y}_{2} \mathrm{O}_{3}, \mathrm{CeO}_{2}$, and $\mathrm{ZrO}_{2}$, respectively, have been considered. Thus, the bonding contributions to $\Delta \alpha^{\prime}$ according to Eqs. (2) and (3) were $-1.5,-0.6$, and $-0.5 \mathrm{eV}$ for the $\mathrm{Zr}-\mathrm{O}-\mathrm{Si}, \mathrm{Zr}-\mathrm{O}-\mathrm{Y}$, and $\mathrm{Zr}-\mathrm{O}-\mathrm{Ce}$ interfaces, respectively. These values reveal that the absolute values of $\Delta \alpha^{\prime}(b)$ vary according to

TABLE I. Electronic parameters that characterize the different $\mathrm{ZrO}_{2} / M \mathrm{O}_{x}$ interface systems described in this paper. Relative coordinates of chemical state vectors are also included.

\begin{tabular}{ccccccc}
\hline \hline $\begin{array}{c}\text { Chemical } \\
\text { state }\end{array}$ & $\begin{array}{c}\text { Interface } \\
\text { system }\end{array}$ & $\begin{array}{c}\Delta \alpha_{\max }^{\prime} \\
(\mathrm{eV})\end{array}$ & $\begin{array}{c}\Delta \alpha^{\prime}(p)_{\max } \\
(\mathrm{eV})\end{array}$ & $\begin{array}{c}\Delta \alpha^{\prime}(b) \\
(\mathrm{eV})\end{array}$ & $\begin{array}{c}\text { Origin of } \\
\mathrm{CSV}\end{array}$ & $\begin{array}{c}\text { Tip } \\
\text { coordinates }\end{array}$ \\
\hline $\mathrm{Zr}^{4+}\left(\mathrm{ZrO}_{2}\right)$ & & & & & $(182.3,1832.7)$ & \\
& $\mathrm{ZrO}_{2} / \mathrm{SiO}_{2}$ & -2.1 & -0.6 & -1.5 & & $(-0.7,2.8)$ \\
& $\mathrm{ZrO}_{2} / \mathrm{Y}_{2} \mathrm{O}_{3}$ & -0.8 & -0.2 & -0.6 & & $(-0.3,1.0)$ \\
& $\mathrm{ZrO}_{2} / \mathrm{CeO}_{2}$ & -0.4 & 0.1 & -0.5 & & $(-0.1,0.4)$ \\
\hline \hline
\end{tabular}


$\mathrm{SiO}_{2}>\mathrm{Y}_{2} \mathrm{O}_{3}>\mathrm{CeO}_{2}$. This tendency is related to the different chemical natures of the three substrate oxides, but this will not be discussed further here.

To proceed to the analysis of the shape of the particles it is necessary to recall some basic assumptions that were used already in a previous work dealing with the deposition of $\mathrm{ZnO}$ on $\mathrm{Al}_{2} \mathrm{O}_{3}$ and $\mathrm{SiO}_{2}{ }^{3}$ The polarization contribution to the modified Auger parameter should depend on the particle height and shape. This is illustrated in the scheme shown in Fig. 6, where it is clear that $\Delta \alpha^{\prime}(p)$ will be different for the atoms of $\mathrm{Zr}$ just at the interface or at regions separated from it. These different contributions to $\Delta \alpha^{\prime}$ can be estimated according to the following expression depending on the location of the $\mathrm{Zr}$ atoms:

$$
\Delta \alpha^{\prime}(x)=\left\{\begin{array}{cc}
\Delta \alpha^{\prime}(b)+\frac{11.4}{d}\left(\frac{1}{n_{l}^{2}}-\frac{1}{n_{s}^{2}}\right) & \text { if } x<d \text { (atoms at the interface) } \\
\frac{11.4}{x}\left(\frac{1}{n_{l}^{2}}-\frac{1}{n_{s}^{2}}\right) & \text { if } x>d \text { (atoms not at the interface) }
\end{array}\right.
$$

where $x$ is the distance of any atomic layer of the particle to the interface. Here, it is assumed that no bonding contribution will affect the $\mathrm{Zr}$ atoms not interacting directly with atoms from the substrate (e.g., by the formation of $\mathrm{Zr}-\mathrm{O}-\mathrm{M}$ cross-linking bonds).

The variation of the averaged Auger parameter of a deposit as a function of its thickness $h$ can be evaluated as the averaged value of $\Delta \alpha^{\prime}(x)$ according to

$$
\Delta \alpha^{\prime}(h)=\frac{\int_{0}^{h} d x \Delta \alpha^{\prime}(x) f(x) e^{-x / \lambda}}{\int_{0}^{h} d x f(x) e^{-x / \lambda}}
$$

where $f(x)$ is the island height distribution of the deposited aggregates.

Using Eqs. (1), (4), and (5), it is possible to calculate the evolution of $\alpha^{\prime}$ with respect to the average particle height by assuming different shapes for the particles. In principle, we will assume two ideal particle shapes. A first one is that of columns (i.e., right prism shape) and a second one is that of hemispheres. For these two models it is possible to calculate a theoretical evolution of the modified Auger parameter as a function of the averaged particle size $\alpha^{\prime}(h)$ as $^{3}$

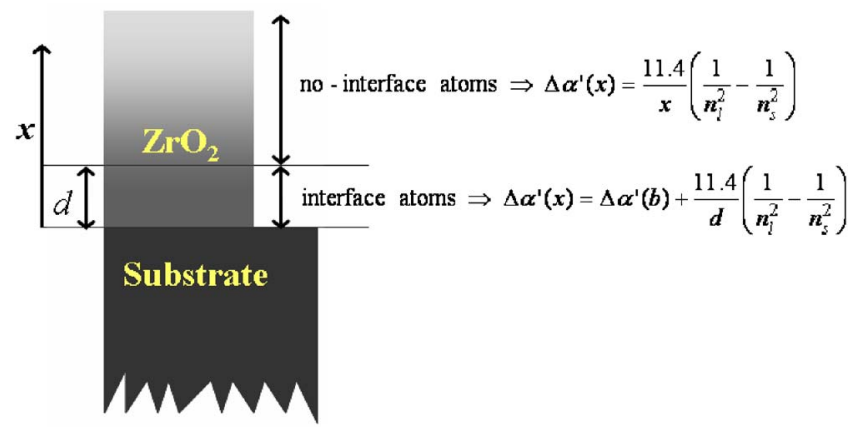

FIG. 6. (Color online) Schematic representation of the expected variation of the modified Auger parameter as a function of the atom position with respect to the substrate interface (lighter color indicates less influence by the substrate).

$$
\alpha^{\prime}(h)=\alpha^{\prime}(\mathrm{Zr}-0-\mathrm{Zr})+\Delta \alpha^{\prime}(h),
$$

where $\Delta \alpha^{\prime}(h)$ is given by Eq. (5). Note that $\alpha^{\prime}(h)$ is sensitive to the shape of particles lying on the surface because particles with different shapes (hemispheres, columns, etc) have different height distribution functions $f(x)$. The calculations have been done for different island heights and show that the expected variation profile of $\alpha^{\prime}(h)$ with the amount of deposited material (equivalent to the height of the particles) is different if the particles are cubic or hemispherical. In Fig. 7 we plot the results of these calculations by assuming these two shapes for the particles. Thus, the variation rate of the Auger parameter is sharper when considering columnar growth than hemispherical particle growth. Figure 7 also shows the experimental variations in the Auger parameter as a function of the average island height determined by the XPS peak shape analysis. Besides, the calculated variation of the Auger parameter depending on whether the growth is columnar or hemispherical are included as full and dashed lines, respectively. It is found that the variation rate of the Auger parameter when considering columnar growth is much faster than in the case of considering hemispherical particle growth. By comparing theoretical and experimental results, it is found that for the $\mathrm{ZrO}_{2} / \mathrm{SiO}_{2}$ system, the experimental variation of the Auger parameter with the island height is clearly better reproduced by a columnar growth type. This result is consistent with the fact that only $80 \%$ of surface coverage is achieved for the highest amount of $\mathrm{ZrO}_{2}$ depos-
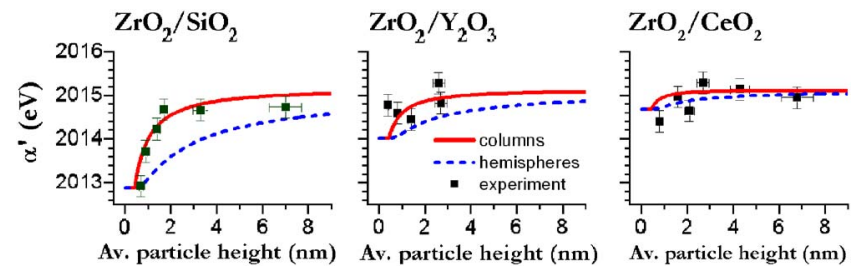

FIG. 7. (Color online) Variation of the modified Auger parameter $\alpha^{\prime}$ as a function of the averaged particle height. Experimental data are indicated as dots, and simulations according to Eq. (6) are indicated as full lines (assuming a columnar growth) and dashed lines (assuming a hemispherical shape growth). 
ited in this experiment on $\mathrm{SiO}_{2}$, as determined previously.

In the cases of $\mathrm{ZrO}_{2} / \mathrm{Y}_{2} \mathrm{O}_{3}$ and $\mathrm{ZrO}_{2} / \mathrm{CeO}_{2}$ the dynamic range of variation of the Auger parameter of $\mathrm{Zr}$ is not large enough to discriminate between the two extreme growth mechanisms considered here.

\section{SUMMARY AND CONCLUSIONS}

The previous results and discussion have shown that $\mathrm{ZrO}_{2}$ deposited at room temperature on $\mathrm{SiO}_{2}, \mathrm{Y}_{2} \mathrm{O}_{3}$, and $\mathrm{CeO}_{2}$ by PECVD present an island growth mechanism. It is apparent that under equivalent conditions, zirconium oxide spreads better on $\mathrm{Y}_{2} \mathrm{O}_{3}$ and $\mathrm{CeO}_{2}$ than on $\mathrm{SiO}_{2}$. Wagner plots and chemical state vectors are also determined for $\mathrm{ZrO}_{2}$ deposited on $\mathrm{SiO}_{2}, \mathrm{Y}_{2} \mathrm{O}_{3}$, and $\mathrm{CeO}_{2}$ substrates. This analysis of electronic parameters provides interesting clues to understand the electronic interactions that develop at the interface. In this regard, it is interesting to point out the large variation that, despite having $\mathrm{Zr}^{4+}-\mathrm{O}$ species in all cases, these parameters may undergo as a function of the size of the $\mathrm{ZrO}_{2}$ particles and their interaction with the substrate.

The information gathered by the study of growth mechanisms can be improved by a combined XPS peak shape and Auger parameter analyses of the systems. This analysis has been only possible for the $\mathrm{ZrO}_{2} / \mathrm{SiO}_{2}$ system, where it has been shown that the zirconia particles present a columnar shape. It is believed that this different behavior is related with a difference in the wetting characteristics of the $\mathrm{ZrO}_{2} / M \mathrm{O}_{x}$ interfaces.

Variations of the Auger parameter can be correlated to the particle size and shape due to their interface interaction in supported particles.

\section{ACKNOWLEDGMENT}

We thank the Spanish Ministry of Science and Education (MAT2004-01558) for financial support.
${ }^{1}$ S. Tougaard, J. Vac. Sci. Technol. A 14, 1415 (1996).

${ }^{2}$ S. Tougaard, Surf. Interface Anal. 26, 249 (1998).

${ }^{3}$ A. I. Martin-Concepción, F. Yubero, J. P. Espinós, A. R. González-Elipe, and S. Tougaard, J. Vac. Sci. Technol. A 21, 1393 (2003).

${ }^{4}$ R. Reiche, S. Oswald, F. Yubero, J. P. Espinós, J. P. Holgado, and A. R. González-Elipe, J. Phys. Chem. B 108, 9905 (2004).

${ }^{5}$ C. Mansilla, F. Yubero, M. Zier, R. Reiche, S. Oswald, J. P. Holgado, J. P. Espinós, and A. R. González-Elipe, Surf. Interface Anal. 38, 510 (2006). ${ }^{6}$ C. D. Wagner, Faraday Discuss. Chem. Soc. 60, 291 (1975).

${ }^{7}$ C. D. Wagner, J. Vac. Sci. Technol. 15, 518 (1978).

${ }^{8}$ G. Moretti, J. Electron Spectrosc. Relat. Phenom. 95, 95 (1998).

${ }^{9}$ A. R. González-Elipe and F. Yubero, Spectroscopic Characterization of Oxide/Oxide Interfaces, in Handbook of Surface and Interfaces of Materials, Vol. 2, edited by H. S. Nalva (Academic, San Diego, 2001), p. 147.

${ }^{10}$ J. P. Espinós, A. I. Martín-Concepción, C. Mansilla, F. Yubero, and A. R. González-Elipe, J. Vac. Sci. Technol. A 24, 919 (2006).

${ }^{11}$ G. Lassaletta, A. Fernández, J. P. Espinós, and A. R. González-Elipe, J. Phys. Chem. 99, 1484 (1995).

${ }^{12}$ R. Reiche, F. Yubero, J. P. Espinós, and A. R. González-Elipe, Surf. Sci. 457, 199 (2000).

${ }^{13}$ J. Morales, J. P. Espinós, A. Caballero, A. R. González-Elipe, and J. A. Mejias, J. Phys. Chem. B 109, 7758 (2005).

${ }^{14}$ D.-S. Lee, W. S. Kim, S. H. Choi, J. Kim, H.-W. Lee, and J.-H. Lee, Solid State Ionics 176, 33 (2005).

${ }^{15}$ J. P. Chang and Y. S. Lin, Appl. Phys. Lett. 79, 3666 (2001)

${ }^{16}$ A. R. González-Elipe, J. P. Espinós, A. Barranco, F. Yubero, and A. Caballero, J. Phys. IV 9, 699 (1999).

${ }^{17} \mathrm{~S}$. Tougaard, QUASES, software package for quantitative XPS/AES of surface nanostructures by inelastic peak shape analysis (see www.QUASES.com.).

${ }^{18}$ S. Tanuma, C. J. Powell, and D. R. Penn, Surf. Interface Anal. 21, 165 (1993).

${ }^{19}$ F. Yubero, J. M. Sanz, J. F. Trigo, E. Elizalde, and S. Tougaard, Surf. Interface Anal. 22, 124 (1994).

${ }^{20}$ C. T. Campbell, Surf. Sci. Rep. 27, 1 (1997).

${ }^{21}$ Handbook of Chemistry and Physics, edited by D. R. Lide (CRC, New York, 2003).

${ }^{22}$ C. Morant, J. M. Sanz, and L. Galán, Phys. Rev. B 45, 1391 (1992).

${ }^{23}$ G. M. Ingo and G. Marletta, Nucl. Instrum. Methods Phys. Res. B 116, 440 (1996).

${ }^{24}$ G. Luckovsky, B. Rayner, Y. Zhang, G. Appel, and J. Whitten, Appl. Surf. Sci. 216, 215 (2003).

${ }^{25}$ J. H. Scofield, J. Electron Spectrosc. Relat. Phenom. 8, 129 (1976).

${ }^{26}$ A. Barranco, F. Yubero, J. P. Espinós, and A. R. González-Elipe, Surf. Interface Anal. 31, 761 (2001).

${ }^{27}$ J. A. Mejías, V. M. Jiménez, G. Lassaletta, A. Fernández, J. P. Espinós, and A. R. González-Elipe, J. Phys. Chem. 100, 16255 (1996). 